Document downloaded from:

http://hdl.handle.net/10251/155499

This paper must be cited as:

Martins, MP.; Cortés, EJ.; Eim, V.; Mulet Pons, A.; Carcel, JA. (2019). Stabilization of apple peel by drying. Influence of temperature and ultrasound application on drying kinetics and product quality. Drying Technology. 37(5):559-568.

https://doi.org/10.1080/07373937.2018.1474476

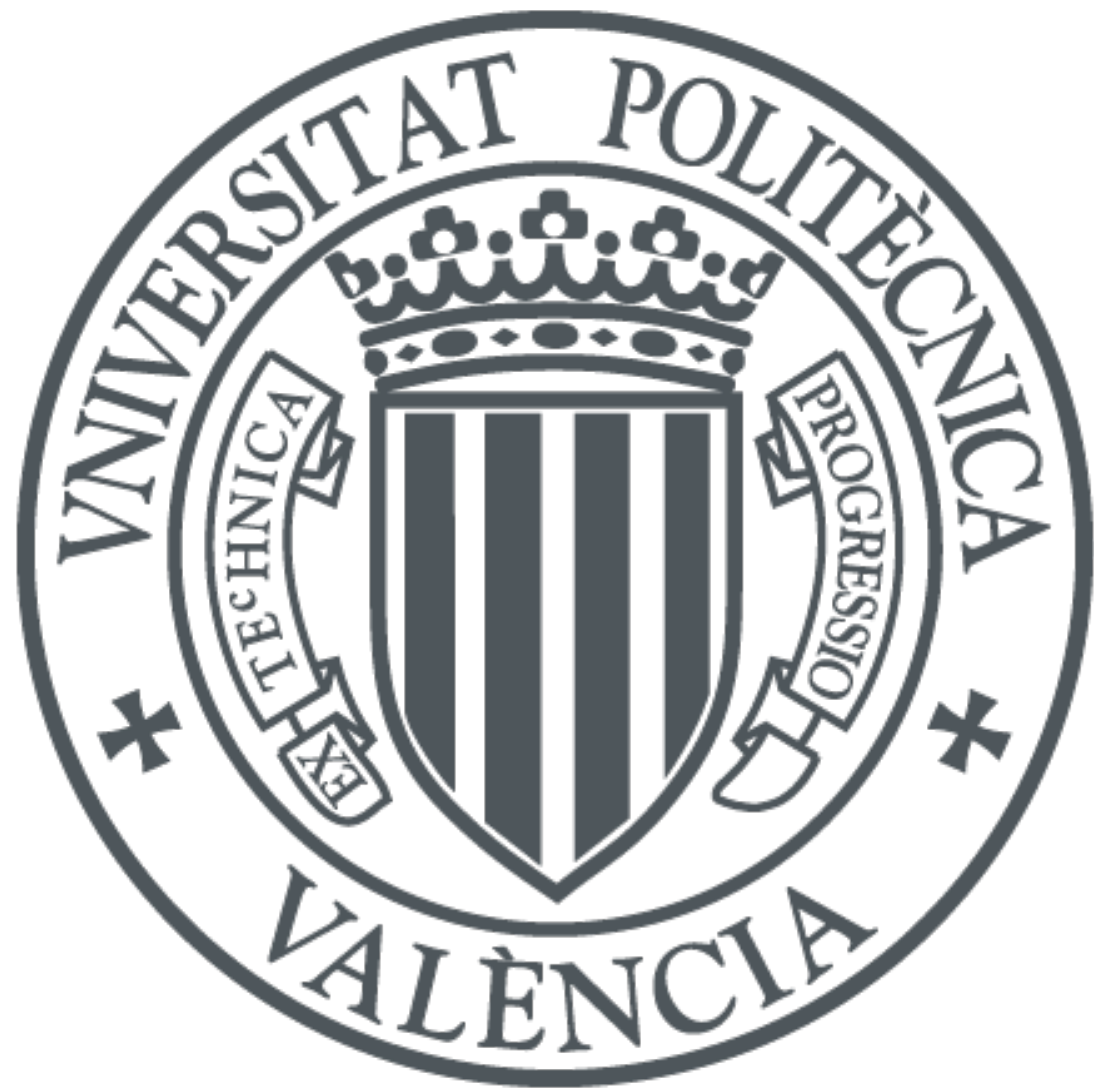

The final publication is available at

https://doi.org/10.1080/07373937.2018.1474476

Copyright Taylor \& Francis

Additional Information

This is an Accepted Manuscript of an article published by Taylor \& Francis Group in Drying Technology on 2019, available online at:

http://www.tandfonline.com/10.1080/07373937.2018.1474476 


\section{STABILIZATION OF APPLE PEEL BY DRYING. INFLUENCE OF TEMPERATURE AND ULTRASOUND APPLICATION ON DRYING KINETICS AND PRODUCT QUALITY}

Matheus P. Martins ${ }^{1}$, Edgar J. Cortés ${ }^{2}$, Valeria Eim ${ }^{3}$, Antonio Mulet ${ }^{4}$, Juan A. Cárcel ${ }^{4^{*}}$

${ }^{1}$ Faculdade de Zootecnia e Engenharia de Alimentos; Universidade de São Paulo, São Paulo, Brazil

${ }^{2}$ Instituto Tecnológico de Veracruz, Veracruz, México

${ }^{3}$ Department of Chemistry. University of the Balearic Islands. Ctra. Valldemossa, km 7.5, 07122. Palma de Mallorca. Spain

${ }^{4}$ ASPA group. Department of Food Technology. Universitat Politècnica de València. Camino Vera s/n, 46022. València. Spain

*Corresponding author. Tel.: +34 96 3879376; Fax: +34 963879839

E-mail address: jcarcel@tal.upv.es

Postal address: Departamento de Tecnología de Alimentos. Universitat Politècnica de València. Camino de Vera s/n, 46022 Valencia (Spain). 


\section{ABSTRACT}

Increasing the value of the waste generated by food processing is a must from an environmental and economic point of view. This paper addresses the influence of drying temperature and ultrasound application on the drying kinetics and quality of apple peel (Royal Gala var.). Samples were dried at $-10,30,50$ and $70^{\circ} \mathrm{C}$ without and with $(50 \mathrm{~W})$ ultrasound application. Color, antioxidant capacity, total phenolic and ascorbic acid content were measured. Ultrasound application and drying temperature significantly shortened the drying time and affected the quality parameters. The drying carried out at $30{ }^{\circ} \mathrm{C}$ with ultrasound application was a fast process that provided samples with good color and antioxidant attributes.

KEYWORDS by-products, drying kinetics, intensification, diffusivity, antioxidant, color 


\section{INTRODUCTION}

The food industry is responsible for generating large quantities of waste with an important environmental impact. Its uses as a fertilizer, after a composting process, or as livestock feed constitute an alternative with either no, or negative, economic impact for the producers. Frequently, the food industry by-products are rich in bioactive compounds [1, 2]. Therefore, it is essential to find efficient and environmentally-friendly options to increase the value of these materials, especially in view of the greater profitability of the process [3].

Worldwide, apple is currently considered to be one of the most widely-consumed fruits $[4,5])$. Apart from the fresh fruit, the best known products originating from apple are juices, jams, breakfast snacks, instant baby food and functional foods [1, 2]. Apples are rated among the richest fruit in free phenolic compounds [6] and antioxidant properties $[4,5]$. It is the apple peel where the antioxidant components are in the highest proportion [7], containing flavonoids which are not present in the pulp, such as cyanidin glycosides and quercetin glycosides [8, 9]. Apple peel is one of the main by-products generated by different manufacturing processes, such as the production of dried apple, apple juice or cider. This by-product can be increased in value by using it as an ingredient with functional properties in different food products, such as bakery products [10, 11].

The re-use of apple peel in other processes requires a prior stabilization step to facilitate its storage and management. Convective hot air drying is one of the most commonlyused techniques in the food industry for this purpose [12] because of its low cost and simplicity. However, drying can produce physical, structural or chemical changes that can affect quality attributes, such as texture, color, flavor or nutritional properties $[5,9$, $13,14]$. In fact, the influence of different drying processes on the antioxidant properties of apple [15, 16, 17] and apple peel [5] has been previously studied. The health requirements of modern-day society and the market demands for high quality products have promoted the innovation and development of alternative drying technologies [18]. 
In this sense, vacuum freeze-drying is considered to be the method that provides the dried products of the highest quality [19]. However, the high energy requirements and the difficulty of achieving a continuous operation [20] make this technique unsuitable for drying low value-added products, such as by-products. However, the use of lowtemperature drying techniques can be of great interest when preserving temperaturesensitive compounds [21]. The slowness of mass transport in these conditions is the main drawback of low-temperature drying. Therefore, it is necessary to intensify the kinetics of these kinds of processes [22].

The application of high-intensity ultrasound emerges as an efficient alternative means of intensifying mass and heat transport and shortening the processing time [23]. The mechanisms involved in ultrasound effects are mainly mechanical, but not thermal [22, 23]. Among others, high-intensity ultrasound generates microstreaming at the solid-gas interfaces, which reduces the thickness of the diffusion boundary layer and, therefore, the external resistance to heat and mass transport. Moreover, it increases the diffusion of water inside solids by the effect of the continuous compression and decompression of the material [24]. Therefore, ultrasound application represents an interesting method of non-thermally intensifying drying processes, not only at high but also at low temperatures $[22,25]$.

Therefore, the aim of this study was to assess the influence of both the drying temperature and ultrasound application on the drying kinetics and quality attributes of apple peel.

\section{MATERIALS AND METHODS}

\section{Sample preparation}

Apples (Royal Gala var.) of Spanish origin, selected with a similar degree of ripeness and appearance, were bought in a local market (Valencia, Spain). They were washed in running water and peeled by using a peeler machine that provides samples that are 
homogeneous in thickness. To inactivate the enzyme, polyphenol oxidase [26], the peel samples were blanched in boiling water for $30 \mathrm{~s}$ [27]. The initial moisture content was determined by the differential weighing of fresh and dried samples in an oven at $60^{\circ} \mathrm{C}$ until constant weight [28].

\section{Drying}

Drying experiments on apple peel were carried out by testing two different mechanisms of water elimination, sublimation and evaporation. The first case corresponded to an atmospheric freeze-drying process and the second to a hot-air drying process. All the experiments were replicated at least three times.

\section{Atmospheric freeze-drying experiments}

Before the atmospheric freeze-drying process, the samples were placed in a sample holder and regularly distributed to ensure afterwards a homogeneous air flow and ultrasonic treatment (Fig. 1). Then, they were frozen in a blast freezer (HIBER, mod. ABB BF051, Italy) at $-35 \pm 1{ }^{\circ} \mathrm{C}$. The frozen samples were transferred to an ultrasoundassisted convective dryer with air recirculation adapted to work at low temperatures [22]. The drying chamber is an aluminum cylinder excited by a piezoelectric transducer (21.9 $\mathrm{kHz}$ ) that produces an inner high-intensity ultrasonic field. During the drying process, the temperature and the air velocity were monitored and controlled by PID algorithms. The experiments were carried out at a constant air velocity of $2 \mathrm{~m} / \mathrm{s}$ and a temperature of $10 \pm 0.5^{\circ} \mathrm{C}$ without (AIR-10) and with (US-10) ultrasound application (absolute electrical input of $50 \mathrm{~W}$ that corresponds to an energy density of $20.5 \mathrm{~kW} / \mathrm{m}^{3}$ if considering the drying chamber volume). The drying kinetics were obtained through the sample's weight measurement during drying at a preset time and the initial moisture content of the apple peel. The experiments were carried out until $85 \%$ of the samples initial weight was lost.

\section{Hot air-drying experiments}


The hot air-drying experiments were performed at 3 different air temperatures, 30, 50 and $70^{\circ} \mathrm{C}$, in an ultrasonically-assisted dryer previously described in the literature [29]. The drying chamber shape and ultrasonic characteristics were similar to those used for atmospheric freeze-drying experiments. The drying experiments were also carried out using an air velocity of $2 \mathrm{~m} / \mathrm{s}$, without (AIR30, AIR50 and AIR70) and with (US30, US50 and US70) ultrasound application (electrical input of $50 \mathrm{~W}$ ) and until the samples lost $85 \%$ of their initial weight.

\section{Modelling}

A diffusion-based model was considered for the purposes of modelling the experimental drying kinetics (Eq. 1). The samples were considered as uniform and isotropic slabs. This can be assumed for hot air-drying experiments but not for atmospheric freeze-drying ones. In this last case, moisture samples remain frozen when the drying takes place. Thus, two layers are found, a frozen inner core and a dehydrated external layer. In this case, therefore, the diffusion model became just an empirical model. However, it permits the comparison between experiments carried out in different drying conditions and the quantification of the influence of temperature and ultrasound application on the drying kinetics [16]. The effective moisture diffusivity was considered to be constant during drying.

$$
\frac{\partial X(x, t)}{\partial t}=D_{e} \frac{\partial^{2} X(x, t)}{\partial x^{2}}
$$

According to Eq. 1, $X$ is the local moisture content of the sample $(\mathrm{kg}$ water $/ \mathrm{kg}$ dry matter, d.m.); $t$ is the drying time (s); $x$ is the direction of the moisture transport (m); and $D_{e}$ is the effective moisture diffusivity $\left(\mathrm{m}^{2} / \mathrm{s}\right)$. To solve Eq. 1 , the moisture distribution inside the samples at the beginning of the drying process was considered to be uniform. As the external layer of apple peel is a natural barrier against dehydration, this was considered as a waterproof surface. Therefore, for modelling purposes, it was considered as a slab geometry with unidimensional moisture flux through a symmetrical sample of twice the 
thickness of apple peel. The external resistance to mass transport was also included in the model by taking into account that the moisture that reaches the sample surface by means of diffusion is transferred to the drying air by convection (Eq. 2)

$-D_{e} \rho_{s S} \frac{\partial x_{p}(L, t)}{\partial x}=k\left(a_{w}(L, t)-\varphi_{\text {air }}\right)$

Where $L$ is the experimental average thickness of the apple peel samples, $\rho_{s s}$ is the density of the dry solid $\left(\mathrm{kg} \mathrm{d} . \mathrm{m} . / \mathrm{m}^{3}\right), k$ is the mass transfer coefficient $\left(\mathrm{kg}\right.$ water $\left./ \mathrm{m}^{2} \mathrm{~s}\right), a_{w}$ is the water activity of the samples and $\varphi_{\text {air }}$ is the relative humidity of the drying air.

An implicit finite difference method was chosen to estimate the model parameters, $D_{e}$ and $k$. For this purpose, an optimization problem was defined to find the $D_{e}$ and $k$ values which minimized the difference between the experimental and calculated average moisture contents. For this purpose, the SIMPLEX method available in the Matlab $2011 B \circledast$ (The Mathworks, Inc, Natick, USA) software was used.

The percentage of explained variance (\% var, Eq. 3) was used to assess the fit of the model

$$
\% \operatorname{var}=\left(1-\frac{s_{x y}^{2}}{S_{y}^{2}}\right) \cdot 100
$$

Where $S^{2}$ and $S^{2}{ }_{x y}$ are the variance of the experimental and the calculated moisture content of apple peel, respectively.

\section{Quality parameters}

Color, antioxidant capacity, total phenolic content and ascorbic acid content were chosen to assess the influence of temperature and ultrasound application during drying on the quality of dried apple peel. For the purposes of their measurement, the dried samples were milled by using a domestic grinder to make a powder product. Then, the samples were sieved and particles of under $1 \mathrm{~mm}$ in size were selected for quality assessment. All the measurements were taken in triplicate

\section{Color}


The color of dried apple peel samples was determined by measuring the CIELAB space color parameters $L^{*}$ (lightness/darkness), $a^{*}$ (redness/greenness) and $b^{*}$ (yellowness/blueness) with a CM-2500d colorimeter (Konica Minolta, Japan). For this purpose, a circular sample holder was filled with the dried apple peel powder and covered with a transparent glass. Readings were made in triplicate for each sample by using a D65 illuminant reference system, with a $10^{\circ}$ opening angle and considering the excluded specular component (SCE). The chroma $\left(C^{*}\right)$, as a measurement of color saturation [30], was obtained from Eq. 4.

$C^{*}=\sqrt{\left(a^{* 2}+b^{* 2}\right)}$

\section{Antioxidant properties of apple peel}

An extract was used to measure the antioxidant properties of dried apple peel. For this purpose, $3 \mathrm{~g}$ of sieved apple peel powder was introduced into $25 \mathrm{~mL}$ of ethanol $(96 \%$ $\mathrm{v} / \mathrm{v})$. In the case of ascorbic acid determination, the proportion used was $3 \mathrm{~g}$ of dried apple peel in $10 \mathrm{~mL}$ of ethanol. The mix was treated for $15 \mathrm{~min}$ in an ultrasonic bath (VMR mod. USC-T, USA). After that, the samples were centrifuged at 1000 r.p.m for 10 min (Selecta, mod. Medifriger BL-S, Spain) and filtered using hydrophobic PTFZ syringe filters of $4.5 \mu \mathrm{m}$ (VMR, USA). The liquid was stored, protected from the light, and quickly processed to determine the antioxidant characteristics.

\section{Antioxidant capacity (AC).}

The antioxidant capacity (AC) of the apple peel extracts was determined by using the Ferric-Reducing Ability Power (FRAP) method, which was described by Benzie and Strain [31]. The FRAP reagent was prepared by adding $2.5 \mathrm{~mL}$ of $10 \mathrm{mM}$ TPTZ (Fluka, Steinheim, Germany) in a solution of $40 \mathrm{mM} \mathrm{HCl}$ (Panreac, Barcelona, Spain) plus 2.5 $\mathrm{mL}$ of $20 \mathrm{mM} \mathrm{FeCl} 3.6 \mathrm{H} 2 \mathrm{O}$ (Panreac, Barcelona, Spain) and $2.5 \mathrm{~mL}$ of acetate buffer 0.3 M (Panreac, Barcelona, Spain), pH 3.6 [32]. For the AC determination, $30 \mu \mathrm{L}$ of each sample were completed with $30 \mu \mathrm{L}$ of distilled water and $900 \mu \mathrm{L}$ of FRAP reagent and 
kept at $37{ }^{\circ} \mathrm{C}$ for 30 minutes. The procedure was performed in triplicate. Using a spectrophotometer (Helios Gamma, Thermo Spectronic, Cambridge, UK) the absorbance was read at $595 \mathrm{~nm}$. A calibration curve was previously determined using ethanol solutions of known Trolox (SigmaeAldrich, Madrid, Spain) concentrations and described as mmol Trolox equivalent per $\mathrm{g}$ of dry mass of apple peel.

\section{Total phenolic content (TPC)}

The Total Phenolic Content (TPC) of the apple peel samples was determined through the Folin-Ciocalteu method [33]. To this end, $100 \mu \mathrm{L}$ of apple peel extract was added to a solution composed of $200 \mu \mathrm{L}$ of Folin-Ciocalteu's phenol reagent (SigmaeAldrich, Madrid, Spain) and $2 \mathrm{~mL}$ of distilled water. The mixture was kept at $25^{\circ} \mathrm{C}$ for $3 \mathrm{~min}$ and then, $1 \mathrm{~mL}$ of $\mathrm{Na}_{2} \mathrm{CO}_{3}$ (Panreac, Barcelona, Spain) solution $\left(\mathrm{Na}_{2} \mathrm{CO}_{3}\right.$ and water $20: 80$, w/v) was added. The absorbance was read with a spectrophotometer (Helios Gamma, Thermo Spectronic, Cambridge, UK) at $765 \mathrm{~nm}$ after the solution was maintained for $1 \mathrm{~h}$ at $20 \pm 1{ }^{\circ} \mathrm{C}$ in the dark. The procedure was performed in triplicate. A standard curve determined with gallic acid hydrate (Sigma Aldrich, Madrid, Spain) at several known concentrations was used to determine the total phenolic content of the samples. The values obtained were described as $\mathrm{mg}$ of Gallic acid equivalent (GAE) per $\mathrm{g}$ of dry mass of apple peel.

\section{Determination of Ascorbic Acid content (AA)}

The ascorbic acid content (AA) was determined by adapting the method proposed by Jagota y Dani [34]. Thus, $0.5 \mathrm{~mL}$ of the extract of apple peel was mixed with $0.5 \mathrm{~mL}$ of a $7.5 \%$ trichloroacetic acid solution. The mixture was stirred slightly, kept for 5 minutes at $4^{\circ} \mathrm{C}$ and filtered $(4.5 \mu \mathrm{m})$. Then, $0.2 \mathrm{~mL}$ of the filtrate were added to $2 \mathrm{~mL}$ of distilled water and $0.2 \mathrm{~mL}$ of Folin-Ciocalteu reagent $(1: 10 \mathrm{v} / \mathrm{v})$. The final solution was kept in darkness at room temperature $\left(20 \pm 1^{\circ} \mathrm{C}\right)$ for 10 minutes. Then, the absorbance was read with a spectrophotometer (Helios Gamma, Thermo Spectronic, Cambridge, UK) at 760 $\mathrm{nm}$. The procedure was performed in triplicate. The concentration of vitamin $\mathrm{C}$ was 
obtained from a calibration curve made up of solutions of known ascorbic acid concentration. All the measurements were taken in triplicate.

The percentage of retention of the different antioxidant parameters was estimated from Eq. 5

Retention $=\frac{P_{f}}{P_{0}} \cdot 100$

where $P_{0}$ is the value of the parameter obtained (AC, TPC and AA) from fresh apple peel and $P_{f}$ corresponds to those of the different dried apple peel samples.

\section{RESULTS AND DISCUSSION}

\section{Drying}

\section{Experimental drying kinetics}

The apple peel samples used in these experiments had an average initial moisture content of $4.99 \pm 0.07$ ( $\mathrm{kg}$ water $/ \mathrm{kg} \mathrm{d.m}$.). Only the falling rate period was observed in the drying kinetics for every experiment carried out.

As can be expected, the temperature of the drying air seriously affected the drying kinetics. As can be seen in Fig. 2, the higher the temperature, the faster the drying process. Thus, the average time needed to achieve a moisture content of $1 \mathrm{~kg}$ of water/ $\mathrm{kg}$ of dry matter (Table 1 ) in experiments carried out at $70^{\circ} \mathrm{C}$ (AIR70, $0.9 \pm 0.1 \mathrm{~h}$ ) was $23 \%$ of those carried out at $30^{\circ} \mathrm{C}(4.1 \pm 0.9 \mathrm{~h})$. The rise in drying temperature increases the energy available in the medium, facilitating both the water mobility inside the product and the water evaporation [35].

As shown in Table 1, considerably more drying time was needed in the atmospheric freeze-drying experiments $(68 \pm 23 \mathrm{~h}$ for AIR-10) than in hot-air drying experiments. At the temperature used in those experiments, very little energy was available to sublimate the frozen water and to transport the vapor from the frozen front to the product surface. 
Moreover, the value of standard deviation also exhibited the great variability of the drying kinetics in these conditions.

The ultrasound application shortened the drying time at every temperature tested. However, the lower the drying temperature, the greater the influence of ultrasound. Thus, under atmospheric freeze-drying conditions $\left(-10^{\circ} \mathrm{C}\right)$, the application of ultrasound shortened the drying time (time needed to achieve $1 \mathrm{~kg}$ of water/kg dry matter) by $69 \%$ (Fig. 3), at $30{ }^{\circ} \mathrm{C}$ the reduction was $58 \%$, at $50{ }^{\circ} \mathrm{C}$ it was $21 \%$ and at $70{ }^{\circ} \mathrm{C}$ it was only 18\%. According to Gallego-Juárez et al. [24], ultrasound application can have a greater effect on the drying process at low temperatures than at high ones. As the mechanical energy supplied by ultrasound is constant in every case, the proportion it represents as regards the total energy available increases the more the temperature falls [36]. Therefore, ultrasound application may be considered an excellent alternative means of improving low-temperature drying processes.

\section{Modelling of drying kinetics}

The modelling of experimental moisture evolution during drying permitted the quantification of the influence of temperature and ultrasound application on kinetics. It must be highlighted that the elimination of the moisture content of apple peel under atmospheric freeze-drying conditions takes place by sublimation, whereas in hot airdrying experiments it is brought about by evaporation. Thus, the identified value of $D_{e}$ under atmospheric freeze-drying conditions (AIR-10) was one order of magnitude smaller than in hot air conditions (Table 1). The $D_{e}$ obtained was in the range of that obtained by other authors at $-10^{\circ} \mathrm{C}$ when drying apple flesh $\left(15.6 \pm 1.3 \cdot 10^{-11} \mathrm{~m}^{2} / \mathrm{s}\right.$ for Santacatalina et al. [16] and $4.09 \pm 0.12 \cdot 10^{-11} \mathrm{~m}^{2} / \mathrm{s}$ for Moreno et al. [17]) using similar modelling. This represents a significant measurement of the great internal resistance to mass transport existing under these conditions, which makes drying a very slow process. As for hot-air drying conditions, the $D_{e}$ obtained were similar to those found by Rodriguez et al. [15] when drying apple cubes. 
Although the diffusion model becomes an empirical model in the case of atmospheric freeze-drying, it was possible to fit the $D_{e}$ identified at the different temperatures to an Arrhenius type equation (Eq. 6).

$D_{e}=D_{0} \exp \left(\frac{E_{a}}{R T}\right)$

Where $D_{0}$ is a pre-exponential factor $\left(\mathrm{m}^{2} / \mathrm{s}\right), E_{a}$ is the activation energy $(\mathrm{kJ} / \mathrm{mol}), R$ the universal gas constant $(\mathrm{kJ} / \mathrm{mol} \mathrm{K})$, and $T$ the temperature $(\mathrm{K})$.

As can be observed in Fig. 4, the fit for AIR experiments was adequate, as shown by the value of the $r^{2}(0.9895)$. The $E_{a}$ obtained $(32.51 \mathrm{~kJ} / \mathrm{mol})$, which constitutes a measurement of the influence of temperature on the kinetics of the process, was in the order of that obtained for similar products [36].

The drying temperature was observed to exert a small, but significant $(p<0.05)$, influence on external resistance. Thus, the mass transfer coefficient $(k)$ identified in AIR70 experiments was 3.5 times larger than that identified in AIR30 experiments (Table 1).

Ultrasound application significantly increased the identified $D_{e}$; the lower the temperature, the more marked this influence became. Thus, the $D_{e}$ identified at $30^{\circ} \mathrm{C}$ with ultrasound application (US30) was 3.8 times bigger than those identified at the same temperature without ultrasound application (AIR30). This increase was 2.0 at $50^{\circ} \mathrm{C}$ and 1.1 at $70^{\circ} \mathrm{C}$. Under atmospheric freeze-drying conditions, the increase in $D_{e}$ produced by ultrasound was near one order of magnitude. Santacatalina et al. [16] found an increase of $500 \%$ when ultrasound was applied during the drying of apple cubes at $-10{ }^{\circ} \mathrm{C}$. Moreno et al. [17] reported similar values in the case of the drying of cylindrical and laminar apple samples. The effects of ultrasound on the reduction of internal mass transport resistance can be related with the successive compression and expansion of the material produced by ultrasonic vibration that makes it easier for the moisture/vapor to move inside the solid sample [18]. The $D_{e}$ identified in the US experiments at the different temperatures also followed an Arrhenius relationship, except in the case of the highest temperature tested, 
$70^{\circ} \mathrm{C}$ (Fig. 4). At this temperature, the energy provided by the drying air could mask the effects provided by the mechanical energy supplied by ultrasound. As can be observed in Fig. 4, the slope of the $\ln \left(D_{e}\right)$ vs $1 / T$ relationship for US experiments (excluding $70^{\circ} \mathrm{C}$ experiments) was gentler than for AIR experiments, as indicate the lower value of the $E_{a}$ : specifically, $25.86 \mathrm{~kJ} / \mathrm{mol}$ for US versus $32.51 \mathrm{~kJ} / \mathrm{mol}$ for AIR. Therefore, the application of ultrasound made the drying less dependent on the drying temperature. The influence of ultrasound was also important in the pre-exponential factor, reducing it from $8.6 \cdot 10^{-5}$ $\mathrm{m}^{2} / \mathrm{s}$ in AIR experiments to $1.6 \cdot 10^{-5} \mathrm{~m}^{2} / \mathrm{s}$ in US experiments.

As regards the influence of ultrasound application on the external resistance to mass transport, this was negligible under the experimental drying conditions considered, the values of the identified mass transfer coefficient being similar (Table 1). It is likely that the external structure of apple peel samples, with one of the sides exhibiting waterproof properties, makes the influence that the microstirring produced by ultrasound at the sample-air interphase exerts on mass transfer negligible.

Taking these results into account, ultrasound application can be an interesting means of attaining a higher drying rate at moderate drying temperatures. The low energy supplied to the transducer $(50 \mathrm{~W})$ may indicate that the application of ultrasound could contribute to a reduction in energy consumption, but this point must be verified with other studies at pilot-plant scale.

\section{Quality properties}

\section{Color}

Color is an important parameter when using dried apple peel as an ingredient. In fact, the pale reddish color of the peel of the Royal Gala variety of apple could be interesting for their use in some bakery products like pies, muffins, etc. For this reason, the influence of the drying process on the final color of dried apple peel was quantified. The results obtained showed differences in the color parameters of samples dried under the different 
conditions tested (Table 2). Thus, as can be observed for AIR experiments, the higher the drying temperature, the higher the $L^{*}$ parameter and the lower the $a^{*}$ and $b^{*}$ parameters. This means that the samples dried at the higher temperatures exhibited more luminosity but less redness and yellowness. On the contrary, the lower the temperature, the lower the degree of luminosity and the more significant the redness and yellowness attributes, characteristics which are highly appreciated in the peel of the Royal Gala variety of apple.

As to the application of ultrasound, it is necessary to differentiate between its application under freeze-drying $\left(-10^{\circ} \mathrm{C}\right)$ or hot $\left(30,50\right.$ and $\left.70^{\circ} \mathrm{C}\right)$ air-drying conditions. In the first case, the application of ultrasound during drying (US-10) provided color parameter values similar to those found in samples dried at $50{ }^{\circ} \mathrm{C}$ without ultrasound application (AIR50). The mechanical stress, linked to oxidizing reactions, produced by ultrasound on the frozen samples during the long drying period involved in these experiments $(21.2 \pm 0.4 \mathrm{~h})$, could produce a similar color degradation to that which takes place when drying at higher temperatures without ultrasound application. As for the US experiments carried out above room temperature, the relationship between color parameters and temperature was similar to that encountered in AIR experiments; that is, the higher the temperature, the greater the value of $L^{*}$ and the lower those of the $a^{*}$ and $b^{*}$ parameters. As is known, chroma constitutes a measurement of the saturation of color. For AIR experiments, the highest value of chroma was found at the lowest drying temperature tested, $-10^{\circ} \mathrm{C}$, which fell when the temperature rose (Table 2). In the case of the influence of US, the US-10 experiments showed significantly $(p<0.05)$ lower chroma than that obtained at the same temperature without ultrasound application (AIR-10). On the contrary, the application of ultrasound increased the chroma value under hot air-drying conditions compared with the experiments carried out at the same temperature without ultrasound application (Table 1). In fact, the value obtained in US30 experiments was not significantly different from that obtained in the AIR-10 ones. This means that it is 
possible to achieve the same saturation of color when drying at $30^{\circ} \mathrm{C}$ with ultrasound application as in a conventional atmospheric freeze-drying process; the drying process is shorter in the first case $(1.7 \pm 0.1 \mathrm{~h}$ vs $68.1 \pm 23.5 \mathrm{~h})$.

\section{Antioxidant properties}

The influence of the drying processes on the antioxidant properties of apple peel was studied from the measurement of the antioxidant capacity (AC), the total phenolic content (TPC) and the ascorbic acid (AA) content.

\section{Antioxidant capacity (AC)}

The antioxidant capacity (AC) of fresh apple peel was $42 \pm 1 \mathrm{mg}$ Trolox $/ \mathrm{g} \mathrm{d} . \mathrm{m}$. This value was higher than those found by other authors when working on apple flesh. Thus, for the Granny Smith variety, Santacatalina et al. [16] reported a value of $8.0 \pm 1.7 \mathrm{mg}$ Trolox/g d.m., Rodriguez et al. [15] obtained $7.7 \pm 1.7 \mathrm{mg}$ Trolox/g d.m. or Moreno et al. [17] 18.2 $\pm 0.7 \mathrm{mg}$ Trolox $/ \mathrm{g}$ d.m. These results agree with the fact that the antioxidant capacity of apple peel is greater than that of the flesh $[27,37]$.

Drying reduced the AC of the apple peel, its retention ranging from 59 to $79 \%$ (Fig. 5A). The level of retention of $A C$ was higher than that obtained by both Rodrigues et al. [15] after drying cubic apple samples at 30,50 and $70{ }^{\circ} \mathrm{C}(49-62 \%)$ and by Santacatalina et al. [16] at temperatures in the range of $-10^{\circ} \mathrm{C}$ to $10^{\circ} \mathrm{C}(50-60 \%)$. On the contrary, it was slightly lower than that reported by Moreno et al. [17] (75-95 \%) for cylindrical and laminar slab apple samples dried at $-10^{\circ} \mathrm{C}$.

No great differences were found between drying experiments carried out at different temperatures (Fig. 5A). Thus, for the AC retention in AIR experiments, only AIR30 dried samples showed a significantly $(\mathrm{p}<0.05)$ higher percentage of $A C$ retention. In the case of US experiments, no significant differences in AC retention were found between the four temperatures tested. When comparing the AC retention in AIR and US experiments carried out at the same temperature, no significant $(p<0.05)$ differences can be observed 
(Fig 5A). Then, from the point of view of the antioxidant capacity of dried apple peel, it can be concluded that $30^{\circ} \mathrm{C}$ is the most interesting temperature of the ones tested, at which to carry out the drying. The application of ultrasound under these conditions did not significantly affect the $\mathrm{AC}$, but may contribute to a significant shortening of the drying time. These results may indicate that optimal drying conditions can be found due to the time-temperature effects and the ultrasound enhancement of oxidizing reactions.

\section{Total phenolic compounds (TPC)}

The concentration of total phenolic compounds is much greater in the apple peel than in the flesh, encouraging new and important studies into its characteristics [27, 38]. The total phenolic compound content of dried apple peels was $16.6 \pm 0.9 \mathrm{mg}$ de GAE/ g d.m. This value was in the range of that found by other authors. Thus, Lata [37] reported a TPC of $5.64 \mathrm{mg} \mathrm{GAE/g} \mathrm{d.m.} \mathrm{in} \mathrm{fresh} \mathrm{apple} \mathrm{peel} \mathrm{(Gala} \mathrm{var.)} \mathrm{while} \mathrm{Henriquez} \mathrm{et} \mathrm{al.} \mathrm{[5]}$ found a value of $35.74 \pm 3.09 \mathrm{mg} \mathrm{GAE} / \mathrm{g}$ d.m. (Granny Smith var.).

As in the case of AC, drying decreased the TPC of apple peel; however, in this case, the drying temperature was found to have an influence (Fig. 5B). Thus, for AIR experiments carried out under hot air-drying conditions, the higher the temperature, the lower the percentage of TPC retention, the difference being significant between AIR30 and AIR70 samples. This can indicate that some of the phenolic compounds present in apple peel are thermo-sensitive in character. Henriquez et al. [5] found a similar relationship between the drying temperature and TPC when working with higher drying temperatures $\left(110-140^{\circ} \mathrm{C}\right)$.

As regards the experiments carried out under atmospheric freeze-drying conditions, the TPC of AIR-10 samples was no different from the TPC obtained for AIR50 samples. The prior freezing of AIR-10 samples could involve some cell rupture that can make the degradation of phenolic compounds easier. This fact, together with the long drying period needed under these conditions, can produce a TPC degradation similar to the one produced by temperatures of around $50^{\circ} \mathrm{C}$. 
The application of ultrasound produced, on the whole, a decrease in TPC retention, which was quite similar for the different temperatures tested (Fig. 5B). However, if AIR and US experiments are compared, only in the drying test carried out at $30^{\circ} \mathrm{C}$ were the differences significant $(p<0.05)$. The mechanical action induced by ultrasound can produce an increase in the oxidation rate, and thus a slight degradation of the phenolic compound. At high temperatures, this can be masked by the effect of that temperature has on thermo-sensitive phenolic compounds (US50 and US70) and, in the case of freeze-drying conditions (US-10), by the phenolic degradation induced by freezing. So, it is only at $30^{\circ} \mathrm{C}$, when there are no temperature or freezing, where the ultrasoundinduced oxidizing effects are significant $(p<0.05)$. Santacatalina et al. [16] also found a greater degradation of TPC in ultrasonically-assisted air freeze-dried samples of apple flesh.

\section{Ascorbic acid content (AA)}

The ascorbic acid content of fresh apple peel was $1.6 \pm 0.2 \mathrm{mg}$ of ascorbic acid $/ \mathrm{g} \mathrm{d} . \mathrm{m}$. As in the case of the other antioxidant characteristics considered, drying produced a partial degradation, the retention ranging from 55 to $89 \%$ of the initial content (Fig. $5 \mathrm{C}$ ). A similar range of percentage of retention was found by Moreno et al. [17] after drying apple flesh samples (2.6 $\pm \mathrm{mg}$ of ascorbic acid/g d.m. of initial content of AA). In drying experiments carried out without ultrasound application, the drying temperature was observed to exert a significant influence. Thus, the percentage of retention of AA was significantly higher in experiments carried out at $30{ }^{\circ} \mathrm{C}$ (AIR30) than at the other temperatures considered (AIR-10, AIR50 and AIR70). As in the case of TPC, at the temperatures above $30{ }^{\circ} \mathrm{C}$, a thermo-degradative effect on $A A$ is observed. Under atmospheric freeze-drying conditions, the prior freezing of the sample and the long drying periods may be the reason for a marked AA degradation.

The application of ultrasound, in general, did not influence the percentage of AA retention. In fact, only at $70{ }^{\circ} \mathrm{C}$ was the AA content of US experiments (US70) 
significantly $(p<0.05)$ higher than in AIR experiments (AIR 70). Therefore, of the drying temperatures considered, $30^{\circ} \mathrm{C}$ was the best one at which to preserve $\mathrm{AA}$, ultrasound application not being considered as a significant factor in AA loss.

\section{CONCLUSIONS}

Temperature and ultrasound application significantly influenced both apple peel drying kinetics and the quality of the dried product. Thus, the higher the temperature, the faster the drying process. The application of ultrasound also shortened the drying time, this reduction becoming more significant as the temperature fell. The atmospheric freezedrying of apple peel was a very time-consuming process, even when intensified by ultrasound. Of the quality parameters considered, the use of ultrasound did not provide a significant, positive impact. On the contrary, the use of ultrasound would enhance oxidizing reactions by increasing oxygen transfer at interfaces. This would indicate that when using ultrasound, an optimal temperature should be found. As for the drying conditions considered, the drying carried out at $30^{\circ} \mathrm{C}$ with ultrasound application was a fast process that provided the samples with the best attributes in terms of color and antioxidant properties. An objective function considering productivity, energy consumption and quality parameters should be defined for future studies.

\section{ACKNOWLEDGMENTS}

The authors acknowledge the financial support of INIA-ERDF throughout the project RTA2015-00060-C04-02 


\section{LITERATURE}

1. Martins, N.; Ferreira, I. C.F.R. Wastes and by-products: Upcoming sources of carotenoids for biotechnological purposes and health-related applications. Trends in Food Science \& Technology 2017, 62, 33-48.

2. Schieber, A.; Stintzing, F. C.; Carle, R. By-products of plant food processing as a source of functional compounds - recent developments. Trends in Food Science and Technology 2001, 12, 401-413.

3. Lowe, E. D.; Buckmaster, D. R. Dewatering makes big difference in compost strategies. Biocycle 1995, 36, 78-82.

4. Lamperi, L.; Chiuminatto, U.; Cincinelli, A.; Galvan, P.; Giordani, E.; Lepri, L.; Del Bubba, M. Polyphenol levels and free radical scavenging activities of four apple cultivars from integrated and organic farming in different Italian areas. Journal of Agriculture and Food Chemistry 2008, 56, 6536-6546.

5. Henríquez, C.; Córdova, A.; Almonacid, S.; Saavedra, J. Kinetic modeling of phenolic compound degradation during drum-drying of apple peel by-products. Journal of Food Engineering 2014, 143, 146-153.

6. Boyer, J.; Liu R. H. Apple phytochemicals and their health benefits. Nutrition Journal 2004, 3, 1-15.

7. Karaman, S.; Tütem, E.; Baskan, K. S.; Apakb, R. Comparison of antioxidant capacity and phenolic composition of peel and flesh of some apple varieties. Journal of the Science of Food and Agriculture 2013, 93, 867-875.

8. Escarpa, A.; Gonzalez, M.C. High-performance liquid chromatography with diode-array detection for the determination of phenolic compounds in peel and pulp from different apple varieties. Journal of Chromatography $A$ 1998, 823, 331-337.

9. Van der Sluis, A.A.; Dekker, M.; Skrede, G.; Jongen, W.M.F. Activity and concentration of polyphenolic antioxidants in apple juice. 1. Effect of existing production methods. Journal of Agricultural and Food Chemistry 2002, 50, 7211-7219. 
10. Rupasinghe, H.P.V.; Wang, L.; Huber, G.M.; Pitts, N.L. Effect of baking on dietary fibre and phenolics of muffins incorporated with apple peel poder. Food Chemistry 2008, 107, 1217-1224

11. O'Shea, N.; Arendt, E.K.; Gallagher, E. Dietary fibre and phytochemical characteristics of fruit and vegetable by-products and their recent applications as novel ingredients in food products. Innovative Food Science and Emerging Technologies 2012, 16, 1-10.

12. Moses, J.A.; Norton, T.; Alagusundaram, K.; Tiwari, B.K. Novel drying techniques for the food industry. Food Engineering Reviews 2014, 6, 43-55.

13. Maskan, M. Drying shrinkage and rehydration characteristics of kiwifruits during microwave drying. Journal of Food Engineering 2001, 48, 177-182.

14. Lewicki, P. P.; Jakubczyk, E. Effect of hot air temperature on mechanical properties of dried apples. Journal of Food Engineering 2004, 64, 307-314.

15. Rodríguez, O.; Santacatalina, J.V.; Simal, S.; Garcia-Perez, J.V.; Femenia, A.; Rosselló, C. Influence of power ultrasound application on drying kinetics of apple and its antioxidant and microstructural properties. Journal of Food Engineering 2014, 129, 21-29.

16. Santacatalina, J.V.; Rodríguez, O.; Simal, S.; Cárcel, J.A.; Mulet, A.; García-Pérez J.V. Ultrasonically enhanced low-temperature drying of apple: Influence on drying kinetics and antioxidant potential. Journal of Food Engineering 2014, 138, 35-44

17. Moreno, C.; Brines, C.; Mulet, A.; Rosselló, C.; Cárcel, J. A. Antioxidant potential of atmospheric freeze-dried apples as affected by ultrasound application and sample surface. Drying Technology 2017, 35, 957-968

18. Musielak, G.; Mierzwa, D.; Kroehnke, J. Food drying enhancement by ultrasound - A review. Trends in Food Science \& Technology 2016, 56, 126141.

19. Pei, F.; Yang, W.; Shi, Y.; Sun, Y.; Mugambi Mariga, A.; Zhao, L.; Fang, Y.; Ma, N.; An, X.; Hu, Q. Comparison of freeze drying with three different combinations of drying methods and their influence on colour, texture, 
microstructure and nutrient retention of button mushroom (Agaricus bisporus) slices. Food Bioprocess Technology 2014, 7, 702-710

20. Li, S.; Stawczyk, J.; Zbicinski, I. CFD. Model of apple atmospheric freezedrying at low temperature. Drying Technology 2007, 25, 1331-1339.

21. Claussen, I.C.; Ustad, T.S.; Strommen, I.; Walde, P.M. Atmospheric freeze-drying - A review. Drying Technology 2007, 25, 947-957.

22. García-Pérez, J.V.; Cárcel, J.A.; Riera, E.; Rosselló, C.; Mulet, A. Intensification of low-temperature drying by using ultrasound. Drying Technology 2012, 30, 1199-1208.

23. Cárcel, J.A.; García-Pérez, J.V.; Riera, E.; Rosselló, C.; Mulet, A. Ultrasonically assisted drying. In Ultrasound in Food Processing; Villamiel, M., García-Pérez, J.V., Montilla, A., Cárcel, J.A., Benedito, J., Eds.; John Wiley \& Sons Ltd.: United Kingdom, 2017; pp 371-391.

24. Gallego-Juárez, J.A.; Riera, E.; de la Fuente-Blanco, S.; Rodríguez-Corral, G.; AcostaAparicio, V.M.; Blanco, A. Application of high-power ultrasound for dehydration of vegetables: processes and devices. Drying Technoogy. 2007, $25,1893-1901$.

25. García-Pérez, J.V.; Cárcel, J.A.; Riera, E.; Mulet, A. Influence of the applied acoustic energy on the drying of carrots and lemon peel. Drying Technology 2009, 27, 281-287.

26. Gao, M.; Liu, C.Z. Comparison of techniques for the extraction of flavonoids from cultured cells of Saussurea medusa Maxim. World Journal of Microbiology and Biotechnlogy 2005, 21, 1461-1463.

27. Wolfe, K.L.; Liu, R.H. Apple peels as a value-added food ingredient. Journal of Agricultural and Food Chemistry 2003, 51, 1676-1683

28. AOAC, Association of Official Analytical Chemist. Official methods of analysis; Arlington: EEUU, 1997.

29. Riera, E.; García-Pérez, J.V.; Acosta, V.M.; Cárcel, J.A.; Gallego-Juárez, J.A. A computational study of ultrasound-assisted drying of food materials. In Multiphysics Simulation of Emerging Food Processing Technologies; Knoerzer, K., Juliano, P., Roupas, P., Versteeg, C. Eds.; IFT Press: Chicago, USA, 2011; pp. 265-302. 
30. Argyropoulos, D.; Tahir Khan, M.; Muller, J. Effect of air temperature and pretreatment on color changes and texture of dried Boletus edulis mushroom. Drying Technology 2011, 29, 1890-1900.

31. Benzie, I.F.; Strain, J.J. The ferric reducing ability of plasma (FRAP) as a measure of "antioxidant power": the FRAP assay. Analytical Biochemistry 1996, 239, 70-76.

32. Pulido, R., Bravo, L., Saura-Calixto, F. Antioxidant activity of dietary polyphenols as determined by a modified ferric reducing/antioxidant power assay. Journal of Agricultural and Food Chemistry 2000, 48, 3396-3402.

33. Gao, X.; Bjork, L.; Trajkovski, V.; Uggla, M. Evaluation of antioxidant activities of rosehip ethanol extracts in different test systems. Journal of the Science of Food and Agriculture 2000, 80, 2021-2027.

34. Jagota, S.K.; Dani, H.M. A new colorimetric technique for the estimation of vitamin C using Folin phenol reagent. Analytical Biochemistry 1982, 127, 178182.

35. Strumillo, C., Kudra, T. Drying: Principles, Applications, and Design. CRC Press, 1986.

36. Do Nascimento, E.M.G.C; Mulet, A.; Ramírez-Ascherí, J.L.; Piler de Carvalho, C.W.; Cárcel, J.A. Effects of high-intensity ultrasound on drying kinetics and antioxidant properties of passion fruit peel. Journal of Food Engineering 2016, 170, 108-118.

37. Lata, B. Relationship between apple peel and the whole fruit antioxidant content: Year and cultivar variation. Journal of Agricultural and Food Chemistry 2007, 55, 663-671.

38. Huber, G.M.; Rupasinghe, H.P.V. Phenolic profiles and antioxidant properties of apple skin extracts. Journal of Food Science 2009, 74, 694-700. 


\section{FIGURE CAPTIONS}

Figure 1. Apple peel distribution in the sample holder before being placed in the dryer.

Figure 2. Experimental drying kinetics of apple peel (Royal Gala var.) at different temperatures and without (AIR) and with ultrasound (US) application.

Figure 3. Experimental atmospheric freeze-drying kinetics of apple peel (Royal Gala var.) without (AIR) and with ultrasound (US) application.

Figure 4. Relationship between the effective diffusivity identified from modelling and the drying air temperature of apple peel dried without (AIR) and with ultrasound (US) application.

Figure 5. Percentage of antioxidant capacity (A), retention of total phenolic content (B) and ascorbic acid $(\mathrm{C})$ of apple peel after drying at different temperatures and without (AIR) and with ultrasound (US) application. 


\section{TABLE CAPTIONS}

Table 1. Drying time needed to obtain a moisture content of $1 \mathrm{~kg}$ water $/ \mathrm{kg}$ dry matter of apple peel at different temperatures and without (AIR) and with (50 W) ultrasound (US) application. Effective diffusivity $\left(D_{e}\right)$ and mass transfer coefficient $(k)$ identified by using a diffusion model. Percentage of explained variance (\% var) by the model. Letters in the same column show homogeneous groups determined by Least Significant Difference $(p<0.05)$ intervals.

Table 2. Color parameters of apple peel dried at different temperatures and without (AIR) or with (50 W) ultrasound (US) application. Same letters in each column show homogeneous groups determined by Least Significant Difference Intervals $(p<0.05)$. 


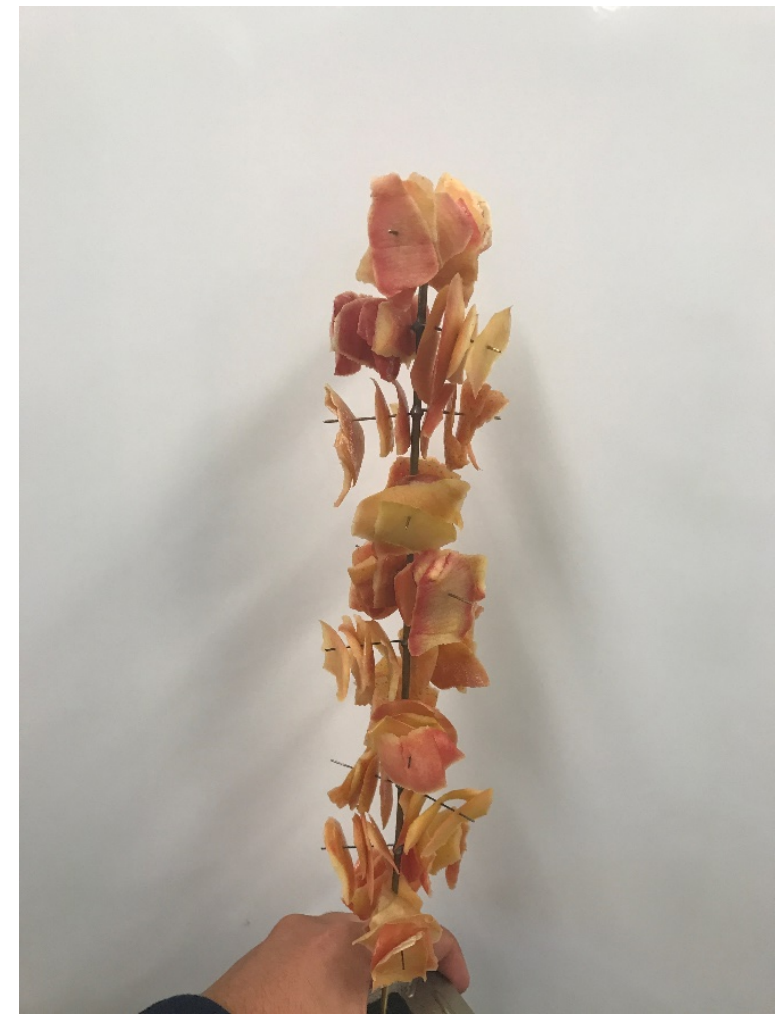

Figure 1. Apple peel distribution in the sample holder before being placed in the dryer 


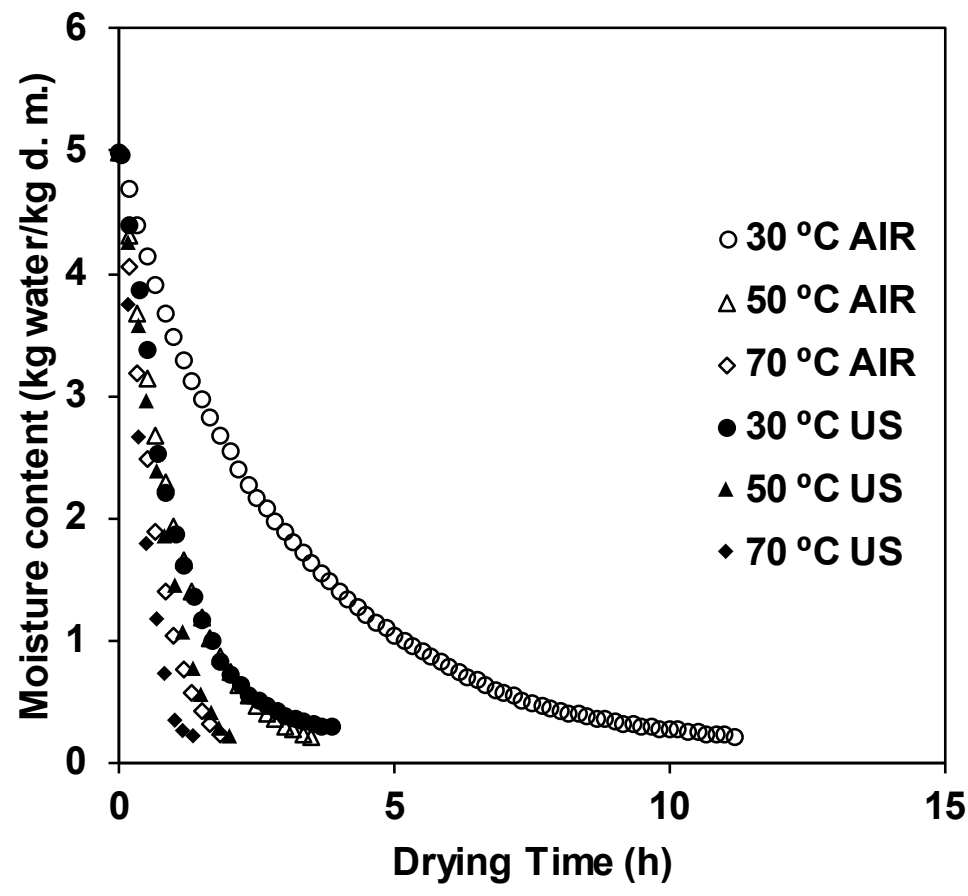

Figure 2. Experimental drying kinetics of apple peel (Royal Gala var.) at different temperatures and without (AIR) and with ultrasound (US) application. 


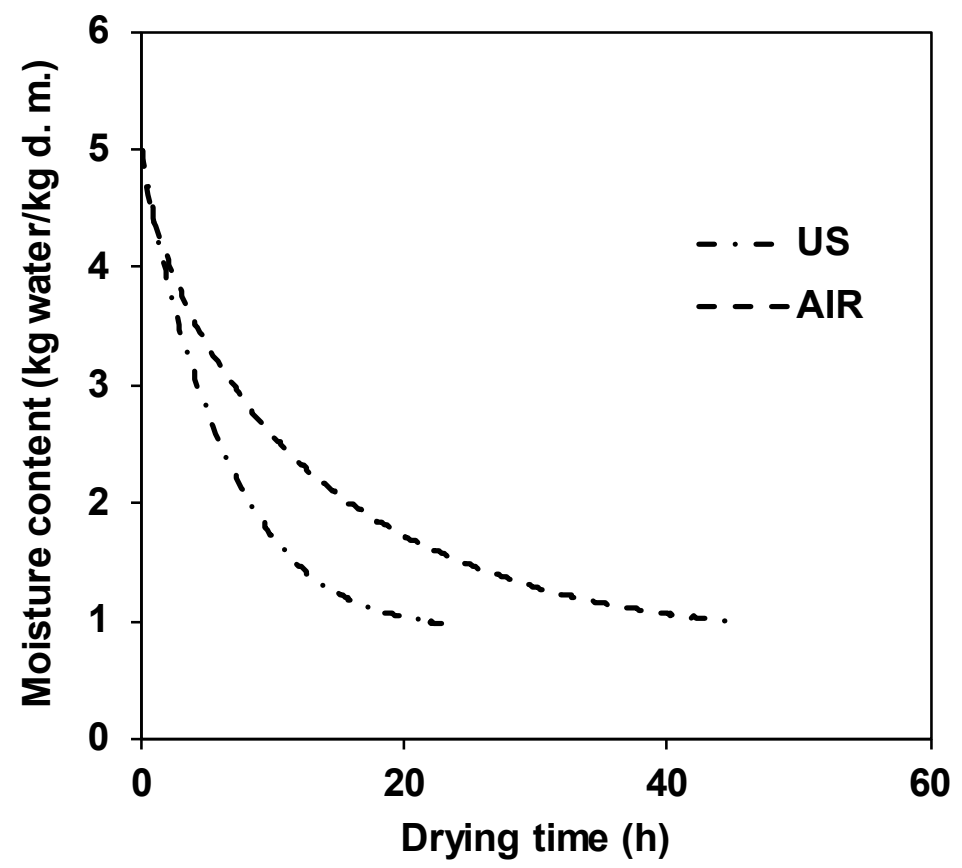

Figure 3. Experimental drying kinetics of apple peel (Royal Gala var.) at different temperatures and without (AIR) and with ultrasound (US) application. 


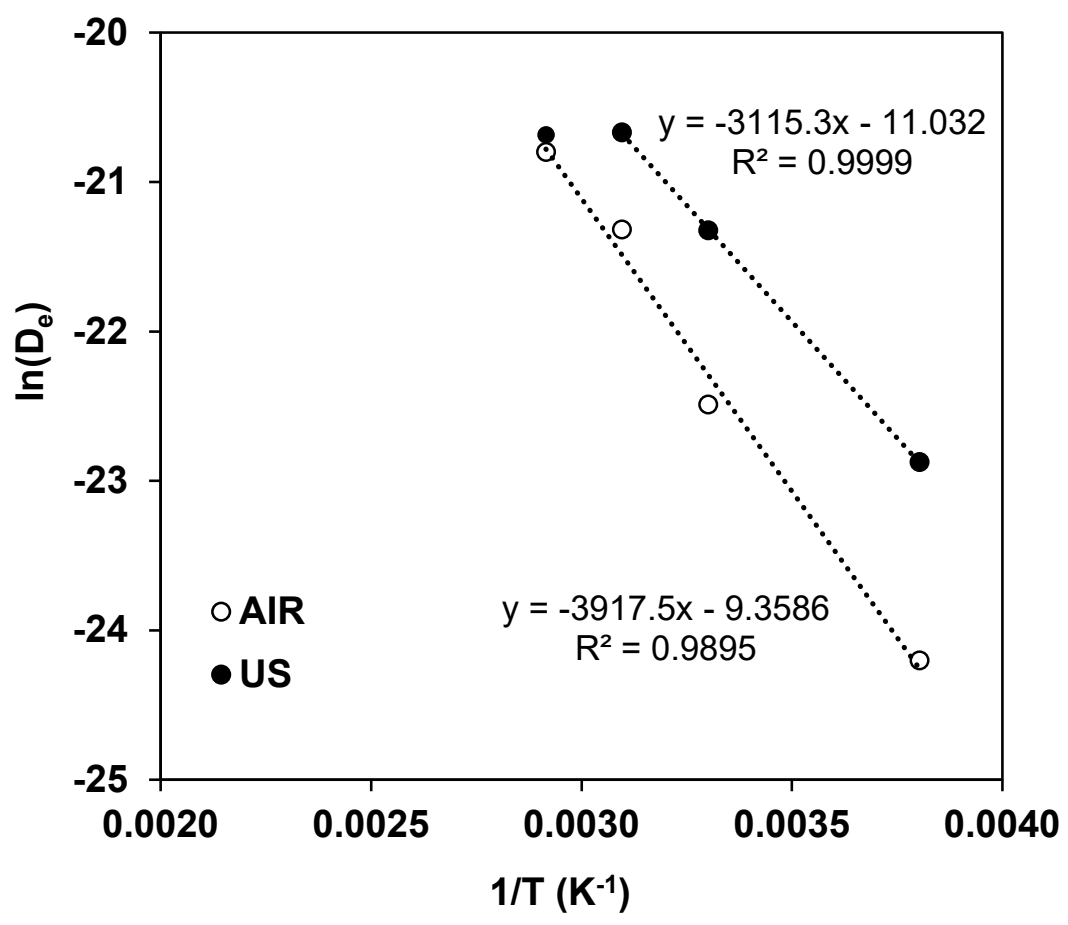

Figure 4. Relationship between the effective diffusivity identified from modelling and the drying air temperature of apple peel dried without (AIR) and with ultrasound (US) application. 

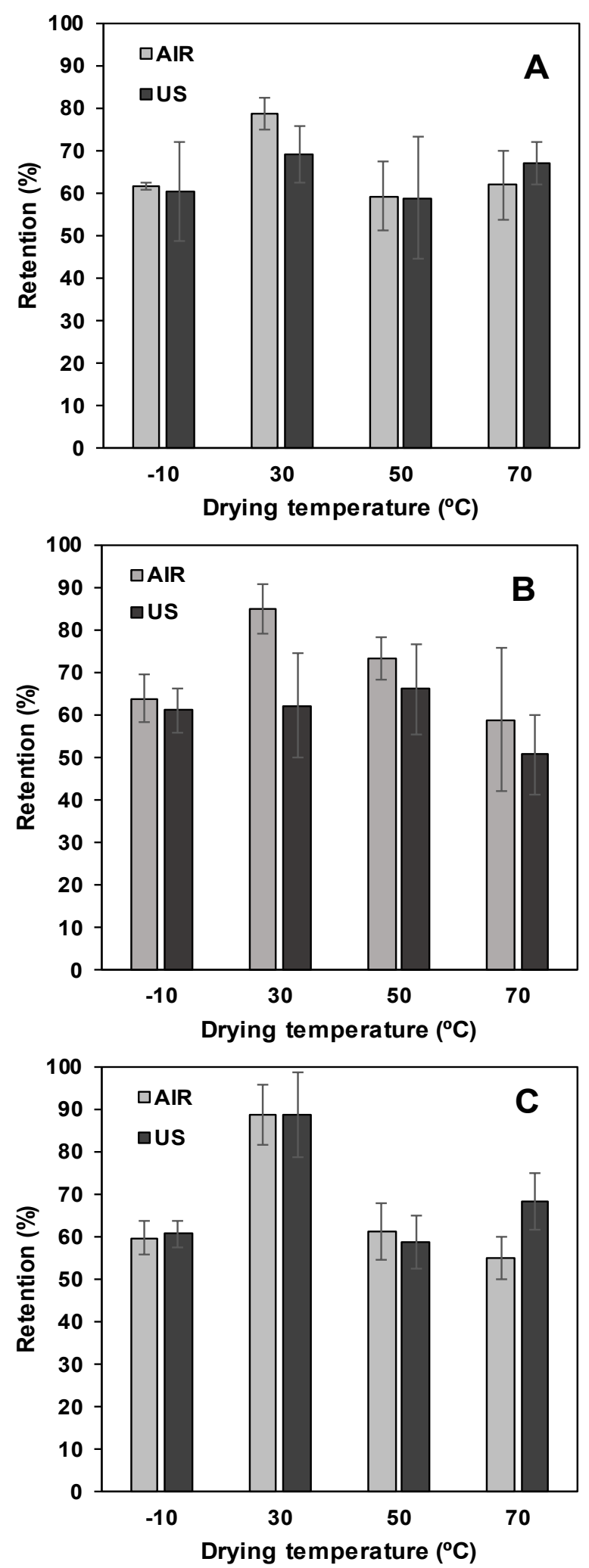

Figure 5. Percentage of antioxidant capacity (A), retention of total phenolic content (B) and ascorbic acid $(C)$ of apple peel after drying at different temperatures and without (AIR) and with ultrasound (US) application. 
Table 1. Drying time needed to obtain a moisture content of $1 \mathrm{~kg}$ water $/ \mathrm{kg}$ dry matter of apple peel at different temperatures and without (AIR) and with (50 W) ultrasound (US)application. Effective diffusivity (De) and mass transfer coefficient (k) identified by using a diffusion model. Percentage of explained variance (\% var) by the model. Letters in the same column show homogeneous groups determined by Least Significant Difference $(p<0.05)$ intervals.

\begin{tabular}{|c|c|c|c|c|}
\hline Treatment & $\begin{array}{l}\text { Drying time } \\
\text { (h) }\end{array}$ & $\begin{array}{c}\text { De } \\
\left(\times 10^{-10} \mathrm{~m}^{2} / \mathrm{s}\right)\end{array}$ & $\begin{array}{c}\mathrm{k} \\
\left(\times 10^{-3} \mathrm{~kg} \text { water } / \mathrm{m}^{2} \mathrm{~s}\right)\end{array}$ & $\%$ var \\
\hline AIR-10 & $68.1 \pm 23.5^{\mathrm{a}}$ & $0.3 \pm 0.1^{a}$ & $1.9 \pm 0.4^{\mathrm{a}}$ & 98.7 \\
\hline AIR30 & $4.1 \pm 0.9^{c}$ & $1.7 \pm 0.6^{b}$ & $0.8 \pm 0.2^{b}$ & 99.1 \\
\hline AIR50 & $1.3 \pm 0.3^{\mathrm{de}}$ & $5 \pm 3^{c}$ & $1.9 \pm 0.5^{\mathrm{a}}$ & 99.6 \\
\hline AIR70 & $0.9 \pm 0.1^{\mathrm{e}}$ & $9 \pm 2^{d}$ & $2.3 \pm 0.2^{\mathrm{a}}$ & 99.9 \\
\hline US-10 & $21.2 \pm 0.4^{b}$ & $1.16 \pm 0.02^{b}$ & $2.0 \pm 0.4^{a}$ & 98.4 \\
\hline US30 & $1.7 \pm 0.1^{d}$ & $5.49 \pm 0.02^{c}$ & $1.8 \pm 0.3^{a}$ & 99.4 \\
\hline US50 & $1.1 \pm 0.1^{\mathrm{e}}$ & $10 \pm 2^{d}$ & $2.0 \pm 0.3^{a}$ & 99.8 \\
\hline US70 & $0.8 \pm 0.2^{\mathrm{e}}$ & $10 \pm 1^{d}$ & $2.4 \pm 0.7^{a}$ & 99.8 \\
\hline
\end{tabular}


Table 2. Color parameters of apple peel dried at different temperatures and without (AIR) or with (50 W) ultrasound (US) application. Same letters in each column show homogeneous groups determined by Least Significant Difference Intervals $(p<0.05)$.

\begin{tabular}{lcccc}
\hline Treatment & $\mathbf{L}^{*}$ & $\mathbf{a}^{*}$ & $\mathbf{b}^{*}$ & $\mathbf{C r}^{*}$ \\
\hline AIR-10 & $49.2 \pm 0.3 \mathrm{a}$ & $21.8 \pm 0.3 \mathrm{a}$ & $17.8 \pm 0.6 \mathrm{ab}$ & $28.5 \pm 0.3 \mathrm{a}$ \\
AIR30 & $50.8 \pm 0.5 \mathrm{~b}$ & $21.8 \pm 0.3 \mathrm{~b}$ & $15.9 \pm 0.3 \mathrm{c}$ & $27.1 \pm 0.2 \mathrm{~b}$ \\
AIR50 & $58.0 \pm 0.3 \mathrm{~d}$ & $17.4 \pm 0.2 \mathrm{~d}$ & $15.5 \pm 0.2 \mathrm{bce}$ & $23.3 \pm 0.1 \mathrm{~d}$ \\
AIR70 & $68.3 \pm 0.6 \mathrm{e}$ & $15.0 \pm 0.6 \mathrm{f}$ & $15.3 \pm 0.3 \mathrm{e}$ & $21.8 \pm 0.4 \mathrm{e}$ \\
\hline US-10 & $58.6 \pm 0.5 \mathrm{~d}$ & $17.6 \pm 0.3 \mathrm{~d}$ & $17.0 \pm 0.6 \mathrm{~b}$ & $24.8 \pm 0.4 \mathrm{c}$ \\
US30 & $54.6 \pm 0.1 \mathrm{c}$ & $21.1 \pm 0.3 \mathrm{~b}$ & $18.7 \pm 0.6 \mathrm{a}$ & $28.5 \pm 0.2 \mathrm{a}$ \\
US50 & $57.5 \pm 0.1 \mathrm{~d}$ & $18.6 \pm 0.2 \mathrm{c}$ & $16.6 \pm 0.7 \mathrm{~b}$ & $25.5 \pm 0.3 \mathrm{c}$ \\
US70 & $58.8 \pm 0.7 \mathrm{~d}$ & $17.8 \pm 0.5 \mathrm{~cd}$ & $15.2 \pm 0.4 \mathrm{e}$ & $23.8 \pm 0.3 \mathrm{~d}$ \\
\hline
\end{tabular}

